\title{
Composição centesimal e aceitação de lingüiça elaborada com reduzido teor de gordura e adicionada de concentrados protéicos de soro de leite
}

\author{
Centesimal composition and acceptance of sausages produced with reduced tenor of fat and added of \\ whey protein concentrates
}

\author{
Ana Cláudia Brandi Ferreira ${ }^{\mathrm{I}}$ Leorges Moraes da Fonseca ${ }^{\mathrm{II}}$ \\ Wagner Luiz Moreira dos Santos ${ }^{\text {II }}$
}

\section{RESUMO}

Este trabalho objetivou avaliar a composição centesimal e aceitação de lingüiças de carne suína fabricadas com Concentrado Protéico do Soro (WPC) ou com concentrado protéico, com elevado teor de $\beta$-lactoglobulina, como substitutos da gordura. Foram realizados sete tratamentos, um grupo controle, contendo $20 \%$ de gordura, e seis tratamentos com reduzido teor de gordura, contendo diferentes níveis de adição de WPC ou de fração de $\beta$-lactoglobulina, a saber, três tratamentos com $10 \%$ de gordura e adição de três diferentes concentrações de WPC $(0,2 \%, 0,5 \%$ e $1,0 \%)$ e três tratamentos com $10 \%$ de gordura e três diferentes níveis de concentrado protéico, com elevado teor de $\beta$-lactoglobulina $(0,1 \%, 0,3 \%$ e $0,6 \%)$. O experimento foi realizado com cinco repetições, contendo todos os tratamentos. Foram realizadas análises em dois tempos de avaliação, um dia após a fabricação $e$ após um período de sete dias de estocagem a aproximadamente $4^{\circ} \mathrm{C}$. Foram realizadas análises de proteína $(\mathrm{g} / 100 \mathrm{~g})$, gordura $\left(\mathrm{g} 100 \mathrm{~g}^{-1}\right)$, umidade $\left(\mathrm{g} 100 \mathrm{~g}^{-1}\right)$, estimativa

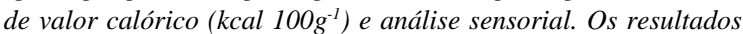
dos teores de proteína, gordura e valor calórico apresentaram diferença $(P \leq 0,05)$ entre o grupo controle e os demais tratamentos. Os resultados das análises de umidade e sensorial não apresentaram diferenças $(P>0,05)$. As proteínas lácteas foram eficazes na substituição da gordura de lingüiças de carne suína, em todos os tratamentos realizados, atendendo às especificações do Regulamento Técnico de Identidade e Qualidade das Lingüiças do Ministério da Agricultura Pecuária e Abastecimento, mantendo a qualidade sensorial.

Palavras-chave: lingüiça, reduzido teor de gordura, concentrado protéico do soro, $\beta-$ lactoglobulina.

\section{ABSTRACT}

The objective of the research was to evaluate the composition and acceptance of pork sausages manufactured with whey protein concentrate (WPC) or with protein concentrate containing high level of $\beta$-lactoglobulin (hereof called $\beta$ lactoglobulin) as fat substitutes. Seven treatments were established, a control containing $20 \%$ of fat, and six containing different levels of WPC or $\beta$-lactoglobulin addition (three treatments containing $10 \%$ of fat and $0.2 \%, 0.5 \%$ or $1.0 \%$ of WPC, and three treatments containing $10 \%$ of fat and $0.1 \%$, $0.3 \%$ or $0.6 \%$ of $\beta$-lactoglobulin). Each treatment was repeated in five batches, and the samples of each batch was evaluated the first and seventh day after processing and storage at $4^{\circ} \mathrm{C}$. The samples were analyzed for protein $\left(g 100 \mathrm{~g}^{-1}\right)$, fat $(\mathrm{g}$ $\left.100 \mathrm{~g}^{-1}\right)$, moisture content $\left(\mathrm{g} 100 \mathrm{~g}^{-1}\right)$, caloric value $(\mathrm{kcal} / \mathrm{g})$ and sensory analyses. The results of protein, fat and caloric value were different between the group control and the other treatments $(P \leq 0.05)$. Additionally, the moisture content and sensory analyses results showed that there was no difference $(P>0.05)$ for the different treatments used in this experiment. The protein concentrates were efficient for the fat substitution in pork sausages, in the treatment levels used in the current experiment, complying with the specifications of the Brazilian legal requirements.

Key words: sausage, reduced fat, whey protein concentrate, $\beta$-lactoglobulin.

\section{INTRODUÇÃO}

Produtos cárneos são, em geral, mais gordurosos que a carne fresca. E segundo AHMED et al. (1990), as lingüiças podem conter de 30 a $40 \%$ de gordura. Dessa forma, existe a possibilidade de substituir parte dessa gordura por outro ingrediente

IEscola de Veterinária (EV), Universidade Federal de Minas Gerais (UFMG). Rua Guajajaras, no 329/1103B, Centro, Belo Horizonte, MG, Brasil. E-mail: anabrandif@hotmail.com. Autor para correspondência.

IIDepartamento de Tecnologia e Inspeção de Produtos de Origem Animal, EV/UFMG, Belo Horizonte, MG, Brasil. 
ou por uma combinação de ingredientes, a fim de tornar esse produto mais saudável (SUMMERKAMP \& HESSER, 1990; TRINDADE, 1998).

Nesse sentido, um dos substitutos de gordura muito estudado como ingrediente utilizado nos embutidos tem sido o concentrado protéico do soro de leite / WPC (YAMAUCHI et al., 1980). Esse produto possui características físico-químicas e sensoriais favoráveis para o seu uso em alimentos. Dentre estas, podem ser citadas: a) boa solubilidade em água; b) capacidade de transportar pequenas moléculas lipofílicas (caso da $\beta$-lactoglobulina); c) ação tensoativa - permite a obtenção e estabilização de sistemas bifásicos (emulsões e espumas); d) propriedades geleificantes - possibilitam a retenção de grandes quantidades de água e outras pequenas moléculas dentro da matriz, conferindo estabilidade aos alimentos (KORHONEN, 2002), além do alto valor nutricional, fornecendo aminoácidos essenciais em quantidade significativa (YAMAUCHI et al., 1980).

Nas carnes e nos produtos cárneos, a solubilidade, hidratação e capacidade de retenção de água são fatores importantes que interferem na textura, suculência e maciez. (MENDES, 1998). Assim, YETIM et al. (2001), estudando o uso de soro do leite em produtos cárneos cominuídos, obtiveram bons resultados em relação às propriedades físico-químicas e sensoriais conferidas pela utilização deste ingrediente em salsichas tipo frankfurter.

O WPC é um produto com elevada proporção de proteínas devido à remoção seletiva de sólidos nãoprotéicos, como a lactose e os minerais (MORR, 1992). Geralmente, as concentrações protéicas em WPC comercial variam entre 34 e 85\% (SUMMERKAMP \& HESSER, 1990). Quando concentrados protéicos são submetidos a fracionamento, são obtidas diversas frações com propriedades funcionais complementares. A proteína $\beta$-lactoglobulina, que representa a maior proteína encontrada no soro do leite e corresponde a $55 \%$ do total dessas proteínas, pode ser isolada por diversas técnicas de fracionamento. Uma fração contendo essa proteína apresenta excelentes propriedades emulsificantes do tipo óleo/água, contendo aproximadamente $90 \%$ de proteína (FONSECA, 1999).

Face ao exposto, este trabalho teve como objetivos avaliar a composição centesimal e aceitação de lingüiças elaboradas com concentrado protéico de soro ou com concentrado protéico contendo elevado teor de $\beta$-lactoglobulina, como substitutos da gordura, e avaliar sua aceitação após estocagem de uma semana.

\section{MATERIAL E MÉTODOS}

Todo o trabalho foi desenvolvido no Departamento de Tecnologia e Inspeção de Produtos de Origem Animal, da Escola de Veterinária, da Universidade Federal de Minas Gerais (UFMG). A tabela 1 registra as fórmulas utilizadas para a elaboração das lingüiças, de acordo com os tratamentos.

As paletas suínas foram desossadas, limpas (sem pele e gordura aparente) e estocadas sob temperatura de aproximadamente $4^{\circ} \mathrm{C}$ juntamente com o toucinho sem pele. A carne foi separada em duas partes, uma para a elaboração do tratamento controle, e a outra para os demais tratamentos. Em seguida, a carne foi moída simultaneamente em moedor marca Siemsen PS22,

Tabela 1 - Formulação das lingüiças de carne suína, segundo os tratamentos.

\begin{tabular}{|c|c|c|c|c|c|c|c|}
\hline \multirow{2}{*}{ Ingredientes } & \multicolumn{7}{|c|}{ 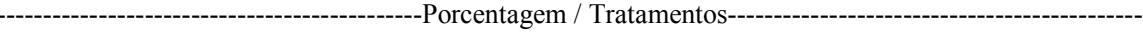 } \\
\hline & $\mathrm{T} 1$ & $\mathrm{~T} 2$ & $\mathrm{~T} 3$ & $\mathrm{~T} 4$ & $\mathrm{~T} 5$ & $\mathrm{~T} 6$ & $\mathrm{~T} 7$ \\
\hline Paleta suína* & 80,0 & 90,0 & 90,0 & 90,0 & 90,0 & 90,0 & 90,0 \\
\hline Gordura suína* & 20,0 & 10,0 & 10,0 & 10,0 & 10,0 & 10,0 & 10,0 \\
\hline Água gelada & 3,0 & 3,0 & 3,0 & 3,0 & 3,0 & 3,0 & 3,0 \\
\hline Sal & 2,0 & 2,0 & 2,0 & 2,0 & 2,0 & 2,0 & 2,0 \\
\hline Condimentos & 0,2 & 0,2 & 0,2 & 0,2 & 0,2 & 0,2 & 0,2 \\
\hline Nitrito / Nitrato & 0,2 & 0,2 & 0,2 & 0,2 & 0,2 & 0,2 & 0,2 \\
\hline Fixador frescal & 0,3 & 0,3 & 0,3 & 0,3 & 0,3 & 0,3 & 0,3 \\
\hline Açúcar & 0,2 & 0,2 & 0,2 & 0,2 & 0,2 & 0,2 & 0,2 \\
\hline Vinho branco & 0,5 & 0,5 & 0,5 & 0,5 & 0,5 & 0,5 & 0,5 \\
\hline WPC & --- & 0,2 & 0,5 & 1,0 & ---- & ---- & ---- \\
\hline$\beta$-lactoglobulina & ---- & ---- & ---- & ---- & 0,1 & 0,3 & 0,6 \\
\hline
\end{tabular}

* Porcentagem sobre o total da matéria-prima cárnea, ou seja, paleta e gordura.

T1= controle; T2= adição de $0,2 \%$ de WPC; T3= adição de $0,5 \%$ de WPC; T4= adição de $1,0 \%$ de WPC; T5= adição de $0,1 \%$ de $\beta$ lactoglobulina; T6= adição de $0,3 \%$ de $\beta$-lactoglobulina; T7= adição de $0,6 \%$ de $\beta$-lactoglobulina.

Ciência Rural, v.39, n.1, jan-fev, 2009. 
equipado com disco de $8 \mathrm{~mm}$, e posteriormente foi colocada em bandeja para adição dos ingredientes, sendo manualmente bem misturada. A massa para a preparação dos seis tratamentos com reduzido teor de gordura foi então dividida somente no momento da adição das proteínas, previamente solubilizadas na água de adição, para diferirem somente em relação a essa variável. Após a incorporação das proteínas, as massas das lingüiças foram acondicionadas em bandejas, devidamente identificadas, tampadas e colocadas para curar por 48 horas, sob refrigeração $\left(\sim 4^{\circ} \mathrm{C}\right)$. Posteriormente foram embutidas em tripa suína de médio calibre ( $30 \mathrm{~mm})$, acondicionadas em sacos plásticos e refrigeradas $\left(\sim 4^{\circ} \mathrm{C}\right)$ até o momento das análises.

Foram realizadas ao todo cinco repetições (cinco semanas não-consecutivas de fabricação), contendo todos os tratamentos. Um dia após cada fabricação das lingüiças foram realizadas as análises físico-químicas e sensoriais dos sete tratamentos, as quais foram repetidas após o armazenamento das amostras sob refrigeração $\left(\sim 4^{\circ} \mathrm{C}\right)$.

O concentrado protéico do soro utilizado na fabricação das lingüiças dos tratamentos 2, 3 e 4 foi o WPC 033RQL, Estabgem ${ }^{\circledast}$, contendo mínimo de 33,5\% de proteínas lácteas. $\mathrm{O}$ concentrado proteíco com alto teor de $\beta$-lactoglobulina, utilizado nos tratamentos 5, 6 e 7 foi o Patent $n^{\circ}$. 6.900.290, com aproximadamente 90\% de proteína (FONSECA \& BRADLEY, 1999).

As análises foram realizadas em duplicata, sendo a proteína determinada pelo método microKjedahl, os lipídeos, pelo método do butirômetro de leite e a umidade, pela perda de água e substâncias voláteis, em estufa a $105^{\circ} \mathrm{C}$, de acordo com Instrução Normativa no. 20 de 21 de julho de 1999 (BRASIL, 1999). O valor calórico das lingüiças foi obtido multiplicandose o teor de lipídeos por $9,0 \mathrm{Kcal} \mathrm{g}^{-1}$ e o teor de proteínas por $4,0 \mathrm{Kcal} \mathrm{g}^{-1}$, sendo os resultados somados posteriormente (GASPAR et al., 1997).

A análise sensorial foi realizada pelo método do Teste Afetivo de Aceitação com uso da Escala hedônica estruturada de oito pontos com 30 provadores não treinados (POSTE et al., 1991; CHAVES, 1990), em cabines individuais do laboratório de análise sensorial. A avaliação sensorial de cada tratamento foi realizada um dia após a fabricação e sete dias após armazenamento sob refrigeração. Aproximadamente 30 gramas de cada amostra foram servidas em copinhos plásticos descartáveis, colocados aleatoriamente em uma bandeja. Cada copinho recebia uma marcação de três dígitos aleatórios, sem relação dos números com os tratamentos. Todas as cabines foram iluminadas com luzes vermelha e azul para não serem percebidas diferenças de coloração entre as amostras. As cabines também possuíam pias com água corrente para a lavagem da boca e um copo com água para beber, palitos e biscoito tipo água e sal. Cada avaliador analisou as sete amostras e marcaram, de acordo com sua opinião, na escala hedônica. As opiniões foram convertida para números de um a oito para se obter a média dos tratamentos e a análise estatística. Os atributos foram: (1) Desgostei extremamente, (2) Desgostei muito, (3) Desgostei moderadamente, (4) Desgostei ligeiramente, (5) Gostei ligeiramente, (6) Gostei moderadamente, (7) Gostei muito e (8) Gostei extremamente.

A análise estatística referente às avaliações físico-químicas, por se tratarem de variáveis quantitativas com distribuição normal, foi avaliada por análise de variância (ANOVA), utilizando o delineamento em blocos ao acaso, sofrendo análise descritiva de acordo com SAMPAIO (2002). A comparação de médias entre tratamentos foi feita por meio do Teste de Student-Newman-Keuls (SNK), sendo fixado um nível de significância de 5\% (SAMPAIO, 2002). Os dados da análise sensorial foram avaliados também por análise de variância (ANOVA), assumindo teste não-paramétrico de Kruskal-Wallis.

\section{RESULTADOS E DISCUSSÃO}

Conforme os dados registrados na tabela 2, houve diferença no teor médio de proteína das lingüiças, nos tratamentos em que foram utilizadas as proteínas lácteas em substituição à gordura. Os teores de proteína das lingüiças dos tratamentos 1 e 4 variaram de $17,5 \%$ a $20,8 \%$, respectivamente. O tratamento 1 apresentou teor protéico semelhante aos tratamentos 5 e $6(\mathrm{P}>0,05)$ e menor que os demais $(\mathrm{P} \leq 0,05)$. A semelhança entre o tratamento 1 com os tratamentos 5 e 6 deve-se à menor inclusão de proteína em substituição à gordura. $\mathrm{O}$ menor teor de proteína do tratamento 1 em relação aos demais foi devido ao seu maior teor de gordura e a não inclusão de proteínas lácteas. Os resultados encontrados neste trabalho atendem ao padrão de identidade e qualidade de lingüiças, que estabelece um mínimo de $12 \%$ de proteínas para lingüiças frescais (BRASIL, 2000). Esses resultados se assemelham aos encontrados por WIRTH (1988), citado por TEIXEIRA (2000), que também encontrou maior teor de proteína em salsichas produzidas com reduzidos teores de gordura. Os teores de proteína nesses tratamentos foram em média 3 a $4 \%$ maiores que os valores de proteínas do tratamento controle, devido ao uso de substitutos de gordura à base de proteínas não-cárneas e à menor inclusão de gordura. 
Tabela 2 - Porcentagens médias de proteína, gordura, umidade e valores calóricos de acordo com os tratamentos.

\begin{tabular}{|c|c|c|c|c|}
\hline \multirow{2}{*}{ Tratamentos } & 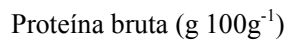 & Gordura (g 100g $\left.{ }^{-1}\right)$ & Umidade (g 100g $\left.\mathrm{g}^{-1}\right)$ & Valor calórico (Kcal $\left.100 \mathrm{~g}^{-1}\right)$ \\
\hline & Média & Média & Média & Média \\
\hline T 1 & $17,5^{\mathrm{b}}$ & $22,16^{\mathrm{a}}$ & $62,8^{a}$ & $269,43^{\mathrm{a}}$ \\
\hline $\mathrm{T} 2$ & $19,86^{\mathrm{a}}$ & $13,37^{\mathrm{b}}$ & $66,6^{\mathrm{a}}$ & $199,78^{b}$ \\
\hline T 3 & $20,50^{\mathrm{a}}$ & $12,83^{\mathrm{b}}$ & $65,7^{\mathrm{a}}$ & $197,48^{\mathrm{b}}$ \\
\hline $\mathrm{T} 4$ & $20,77^{\mathrm{a}}$ & $12,74^{\mathrm{b}}$ & $66,0^{\mathrm{a}}$ & $197,70^{\mathrm{b}}$ \\
\hline T 5 & $18,88^{\mathrm{ab}}$ & $13,51^{\mathrm{b}}$ & $66,6^{\mathrm{a}}$ & $197,08^{\mathrm{b}}$ \\
\hline T 6 & $19,34^{\mathrm{ab}}$ & $12,73^{\mathrm{b}}$ & $66,7^{\mathrm{a}}$ & $191,93^{b}$ \\
\hline T 7 & $20,38^{\mathrm{a}}$ & $12,89^{\mathrm{b}}$ & $66,2^{\mathrm{a}}$ & $197,53^{b}$ \\
\hline
\end{tabular}

a,b Letras iguais na mesma coluna indicam não haver diferença estatística significativa de acordo com o teste de $\mathrm{SNK}(\mathrm{P}<0,05)$. $\mathrm{T} 1=$ controle; $\mathrm{T} 2=$ adição de $0,2 \%$ de WPC; T3= adição de $0,5 \%$ de WPC; T4= adição de $1,0 \%$ de WPC; T5= adição de $0,1 \%$ de $\beta$ lactoglobulina; T6= adição de $0,3 \%$ de $\beta$-lactoglobulina; T7= adição de $0,6 \%$ de $\beta$-lactoglobulina.

Em relação à porcentagem média de gordura, foi observado que o tratamento 1 , que corresponde ao controle, elaborado com $20 \%$ de gordura, apresentou diferença em relação aos demais produzidos com $10 \%$ de gordura $(\mathrm{P} \leq 0,05)$. Porém, não foram obsevadas diferenças $(\mathrm{P}>0,05)$ entre os demais tratamentos com reduzidos teores de gordura.

Neste experimento, teor médio de gordura das lingüiças dos tratamentos 2, 3, 4, 5, 6 e 7 apresentaram uma redução de aproximadamente $40 \%$ das gorduras totais e uma diferença, na redução, maior que $3 \mathrm{~g}$ de gordura/ $100 \mathrm{~g}$ de sólidos em relação ao grupo controle (tratamento 1). Esse resultado enquadra as lingüiças desses tratamentos como produtos light, isto é, produtos com baixos teores de gordura em relação ao produto convencional, conforme a Portaria do Ministério da Saúde no 27, de 13 de janeiro de 1998 (BRASIL,1998). Esses produtos também atendem ao padrão de identidade e qualidade de lingüiças frescais, que estabelece teor máximo de $30 \%$ de gordura para estas (BRASIL, 2000). SEABRA et al. (2002) também encontraram menores teores de gordura em hambúrguer de carne ovina quando utilizaram fécula de mandioca e farinha de aveia como substitutos de gordura na sua formulação.

O teor de umidade das lingüiças, avaliado um dia após o processamento destas, não diferiu significativamente entre os tratamentos $(\mathrm{P}>0,05)$, pois todas foram produzidas, de acordo com as regulamentações, com a adição de 3\% de água. Os resultados do teor de umidade das lingüiças em todos os tratamentos atendem ao padrão, que estabelece máximo de $70 \%$ de umidade para as lingüiças frescais (BRASIL, 2000). Perdas de umidade podem ocorrer na estocagem de produtos cárneos, devido à diminuição da força iônica dos sistemas protéicos, que, com o decorrer do tempo de armazenamento, diminuem a capacidade de ligação com a água, liberando-a (CLAUS et al.,1990; WIRTH, 1988). No entanto, TEIXEIRA (2000) observou um aumento no teor de umidade de salsichas de carne de aves com diferentes teores de água e proteína isolada de soja em substituição à gordura, com o aumento do período de armazenamento $(\mathrm{P} \leq 0,05)$, provavelmente devido às propriedades higroscópicas deste ingrediente protéico.

O valor calórico diferiu significativamente da amostra controle, com maior porcentagem de gordura ( $22 \%$ ), em relação aos demais tratamentos que continham índices de aproximadamente $13 \%$ de gordura. Não houve diferenças entre os tratamentos com o nível reduzido de gordura $(\mathrm{P}>0,05)$. Esse resultado se deve principalmente aos valores encontrados para os teores de gordura, pois nestas análises o tratamento controle também difere dos demais tratamentos $(\mathrm{P} \leq 0,05)$. A porcentagem de gordura é o que mais influencia os valores calóricos, estando de acordo com o esperado, embora a proteína também exerça influência no valor calórico. O cálculo do valor calórico nesses tratamentos baseia-se principalmente na quantidade de gordura e de proteína existente nos produtos. Estes resultados estão de acordo com WIRTH (1991), citado por TEIXEIRA (2000), o qual concluiu que produtos com $15 \%$ de lipídeos e $70 \%$ de carne magra, com proteína aproximada de $16 \%$,

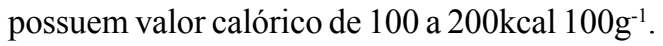

Neste experimento, o valor calórico das lingüiças dos tratamentos 2, 3, 4, 5, 6 e 7 apresentaram uma redução de aproximadamente $30 \%$ e uma diferença maior que $40 \mathrm{kcal}$ por $100 \mathrm{~g}$ de sólidos em relação ao tratamento 1 (grupo controle), podendo ser qualificadas como produtos light.

Os resultados da análise estatística para a avaliação sensorial podem ser vistos na tabela 3 . Os

Ciência Rural, v.39, n.1, jan-fev, 2009. 
Tabela 3 - Médias dos resultados das análises sensoriais de acordo com os tratamentos e as semanas de análises.

\begin{tabular}{llllllll}
\hline Dias & T 1 & T 2 & T 3 & T 4 & T 5 & T 6 \\
\hline 1 & 6,1 & 6,3 & 6,0 & 6,2 & 6,2 & 6,1 & 6,0 \\
7 & 6,3 & 6,3 & 6,4 & 6,4 & 6,2 & 6,3 \\
\hline
\end{tabular}

Os resultados não apresentaram diferença estatística significativa nas linhas e colunas $(\mathrm{P}<0,05)$

$\mathrm{T} 1=$ controle; T2= adição de $0,2 \%$ de WPC; T3= adição de $0,5 \%$ de WPC; T4= adição de $1,0 \%$ de WPC; T5= adição de $0,1 \%$ de $\beta$ lactoglobulina; T6= adição de $0,3 \%$ de $\beta$-lactoglobulina; T7= adição de $0,6 \%$ de $\beta$-lactoglobulina

Descritores da análise sensorial pontuados:

(1)Desgostei extremamente,

(2)Desgostei muito,

(3)Desgostei moderadamente,

(4)Desgostei ligeiramente,

(5)Gostei ligeiramente,

(6)Gostei moderadamente,

(7)Gostei muito,

(8)Gostei extremamente.

resultados mostram que não houve diferença entre os tratamentos quanto à avaliação sensorial $(\mathrm{P}>0,05)$. Esses resultados também foram semelhantes em relação às semanas das análises $(\mathrm{P}>0,05)$. As notas médias da avaliação sensorial variaram de 6,03 a 6,27 e 6,23 a 6,41 nos dias um e sete, respectivamente. Modificações físicoquímicas podem ocorrer no período de armazenamento devido, por exemplo, à atuação de bactérias ácido-láticas, entretanto, são bem aceitas sensorialmente.

$\mathrm{Na}$ avaliação das características físicas e sensoriais de lingüiças de carne suína processadas com vários níveis de adição de água e de gordura, AHMED et al. (1990) também não encontraram diferença na palatabilidade global entre essas lingüiças. Com base nesses dois experimentos, foi observado que, tanto o aumento na adição da quantidade de água, como a adição de proteínas que tenham a função de ligação com a água, mantém a qualidade sensorial das lingüiças de carne suína. Entretanto, com adição de água, as perdas ao cozimento são consideráveis e estatisticamente significativas $(\mathrm{P} \leq 0,05)$, de acordo com os mesmos autores.

\section{CONCLUSÕES}

As proteínas lácteas foram eficazes para substituírem 50\% do índice de gordura nas lingüiças de carne suína, e o período de sete dias de armazenamento à temperatura de refrigeração não interferiu na sua qualidade sensorial. A composição centesimal das lingüiças, em todos os tratamentos, atendeu as especificações do Regulamento Técnico de Identidade e Qualidade do Ministério da Agricultura Pecuária e Abastecimento.

\section{AGRADECIMENTOS}

Os autores agradecem à Universidade Federal de Minas Gerais, Escola de Veterinária da UFMG e à Fundação Coordenação de Aperfeiçoamento de Pessoal de Nível Superior (CAPES).

\section{COMITÊ DE ÉTICA E BIOSSEGURANÇA}

Este trabalho foi aprovado pela Comissão de Ética em Pesquisa da UFMF (COEP) em 23 de maio de 2006, estando de acordo com normas éticas de pesquisas envolvendo seres humanos.

\section{REFERÊNCIAS}

AHMED, P.O. et al. Physical and sensory characteristics of low-fat fresh pork sausage processed with various level of added water. Journal of Food Science, v.55, n.3, p.625-628, 1990.

BRASIL. Ministério da Saúde. Secretaria de Vigilância Sanitária. Portaria no 27. Regulamento Técnico referente à Informação Nutricional Complementar, 1998. Acesso em 20 de fev. 2006. Online. Disponível na Internet: http:// www.anvisa.gov.br/legis/portarias/27_98.htm.

BRASIL. Instrução Normativa no 20 de 21 de julho de 1999. Anexo - Métodos analíticos físico-químicos para controle de produtos cárneos e seus ingredientes - sal e salmoura. Ministério da Agricultura, 1999.

BRASIL. Instrução Normativa no 4 de 31 de março de 2000. Anexo - Regulamento Técnico de Identidade e Qualidade de Lingüiça. Ministério da Agricultura, 2000.

CHAVES, J.B.P. A análise sensorial na indústria de laticínios. Instituto Cândido Tostes, v.45, p.38-52, 1990.

CLAUS, J.R. et al. Low fat, high added water bologna effects of massing, pre-blending, and time of addition of water and fat on physical and sensory characteristics. Journal of Food Science, v.55, n.2, p.338-345, 1990.

Ciência Rural, v.39, n.1, jan-fev, 2009. 
FONSECA, L.M. Fractionation of whey proteins by complex formation and membrane filtration. 1999. $250 \mathrm{f}$. Tese (Doutorado em Ciência de Alimentos) - University of Wisconsin, Madison.

FONSECA, L.M.; BRADLEY JR, R.L. Fractionation of whey proteins by complex formation - US Patent n. 6,900,290. Journal of Dairy Science, v.82, Suppl.1, p.27, 1999.

GASPAR, A. et al. Salsichas tipo Viena com teor reduzido de gordura animal. Higiene Alimentar, v.11, n.52, p.32-37, 1997.

KORHONEN, H. Technology option for new nutritional concepts. International Journal of Dairy Technology, v.55, p.79-88, 2002.

MENDES, A.C.R. Propriedades funcionais das proteínas: sua importância e aplicabilidade em produtos alimentícios. Higiene Alimentar, v.12, n.56, 1998.

MORR, C.V. Improving the texture and functionality of whey protein concentrate. Food Technology, v.46, n.1, p.110-113, 1992.

POSTE, L.M. et al. Laboratory methods for sensory analysis of food. Otta: Canada Communication Group, 1991. $91 \mathrm{p}$.

SAMPAIO, I.B.M. Estatística aplicada à experimentação animal. 2.ed. Belo Horizonte: Fundação de Ensino e Pesquisa em Medicina Veterinária e Zootecnia, 2002. 265p.
SEABRA, L.M.A.J. et al. Fécula de mandioca e farinha de aveia como substitutos de gordura na formulação de hambúrguer de carne ovina. Ciência e Tecnologia de Alimentos, v.22, n.3, p.244-248, 2002.

SUMMERKAMP, B.; HESSER, M. Fat Substitute update. Food Technology, v.44, n.3, p.92-97, 1990.

TEIXEIRA, C.T. Avaliação microbiológica, físico-química e sensorial de salsicha de carne de ave com diferentes teores de água e proteína isolada de soja em substituição a gordura. 2000. 80f. Dissertação (Mestrado em Medicina Veterinária) - Faculdade de Veterinária, UFF, Niterói.

TRINDADE, C.S.F. Produtos cárneos com baixo teor de gordura. Higiene Alimentar,v.12,n.56, p.13-18, 1998.

WIRTH, F. Technologies for making fat-reduced meat products. Fleischwirtsch, v.68, n.9, p.1153-1156, 1988.

WIRTH, F. Reducing the fat and sodium content of meat products. Fleischwirtsch, v.71, n.3, p.294-297, 1991.

YAMAUCHI, K. et al. Emulsifying properties of whey protein. Journal of Food Science, v.45, n.5, p.1237-1242, 1980.

YETIM, H. et al. Usinfg fluid whey in comminuited meat products: effects on technological, chemical and sensory properties of frankfurter-type sausages. Food Research International, v.34, p.97-101, 2001. 